$\underline{\text { Review Article }}$

\title{
MORONIC ACID: A REVIEW
}

\author{
RITU RANI, AJEET PAL SINGH, AMAR PAL SINGH
}

St. Soldier Institute of Pharmacy, Lidhran Campus, Behind NIT (R. E. C), Jalandhar-Amritsar by pass NH-1 Jalandhar 144011, Punjab, India Email: reetuchahal27@gmail.com

Received: 04 May 2021, Revised and Accepted: 02 Jul 2021

\section{ABSTRACT}

Moronic acid is a pentacyclic triterpenoid made up of olean-18-ene with an oxo group at position 3 and a carboxy group at position 28. It's made from an oleanane hydride. A few investigations have demonstrated that Moronic acid a wide scope of pharmacological effects such as Antidiabetic activity, Anti-AIDS agents, Chemotherapeutic agents, Virus lytic, Anti-HIV, Cytotoxic activity, Anti-herpes, Antimicrobial activity, Ribosome-loaded mRNAs.

Keywords: Moronic acid, Triterpene, Synonyms, Structure, Pharmacological effects

(c) 2021 The Authors. Published by Innovare Academic Sciences Pvt Ltd. This is an open access article under the CC BY license (https://creativecommons.org/licenses/by/4.0/) DOI: https://dx.doi.org/10.22159/ijcpr.2021v13i5.1903 Journal homepage: https://innovareacademics.in/journals/index.php/ijcpr

\section{INTRODUCTION}

Moronic acid is a naturally occurring triterpene. Moronic acid may be extracted from Rhus javanica, a sumac plant that has traditionally been believed to have medicinal qualities. The chemical has also been extracted using mistletoe (Phoradendron reichenbachianum). Bevirimat, a derivative of the related triterpenoid betulinic acid, is being researched as an anti-HIV drug; however, moronic acid has been shown in vitro to have better antiviral activities than bevirimat. A moronic acid derivative with EC50 values of $0.0085 \mathrm{M}$ against NL4-3, $0.021 \mathrm{M}$ against PI-R (a multiple protease inhibitor resistant strain), and $0.13 \mathrm{M}$ against FHR-2 (a ribavirin-resistant HIV strain) showed potent anti-HIV activity (bevirimat). This derivative, which is also effective against the herpes simplex virus 1 , has emerged as a promising new candidate for clinical trials $[1,2]$.

\section{Chemical structure moronic acid [1]}

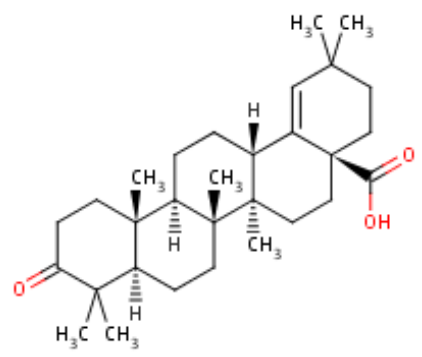

Synonyms [1]

Moronic acid

6713-27-5

Moronicacid

3-0xoolean-18-en-28-oic acid

\section{MLS000563430}

(4aS,6aR,6aR,6bR,8aR,12aR,14aS)-2,2,6a,6b,9,9,12a-heptamethyl10-oxo-4,5,6,6a,7,8,8a,11,12,13,14,14a-dodecahydro-3H-picene-4acarboxylic acid

\section{Chemical properties of moronic acid}

Appearance: Powder, Formula: $\mathrm{C}_{30} \mathrm{H}_{46} \mathrm{O}_{3}$, Molecular Weight.: 454.7, Type of Compound: Triterpenoids, Storage: Desiccate at-20 ${ }^{\circ} \mathrm{C}$, Solubility: Soluble in Chloroform, Dichloromethane, Ethyl Acetate, DMSO, Acetone, etc. Generally, Warm the tube to $37^{\circ} \mathrm{C}$ and shake it in the ultrasonic bath for a while to increase solubility. The stock solution may be kept for many months at- $20^{\circ} \mathrm{C}$. We suggest that you make the solution and utilise it on the same day. If the test schedule demands it, the stock solutions may be produced ahead of time, but they must be sealed and kept below $-20^{\circ} \mathrm{C}$. The stock solution may be maintained for many months in most cases. We suggest allowing the vial to come to room temperature for at least an hour before using it.

\section{Source of moronic acid}

This product is isolated and purified from the herbs of Rhus chinensis

\section{Pharmacological activities of moronic acid}

The pharmacological activities of Moronic acid are briefly discussed are

\section{Antidiabetic activity}

The anti-diabetic activity of four structurally similar triterpenic acids: ursolic (RE-01), oleanolic (RE-02), moronic (RE-03), and morolic (RE-04) acids, when taken orally. The antidiabetic effects of these triterpenes $(50 \mathrm{mg} / \mathrm{kg})$ on STZ-nicotinamide diabetic rats were evaluated in an acute experiment. In compared to the control group, all drugs exhibited substantial antidiabetic efficacy (p0.05). Compounds' inhibitory efficacy against protein tyrosine phosphatase 1B (PTP-1B) was also tested in vitro. The enzymatic activity was nearly totally suppressed at $50 \mathrm{M}$. The crystal structure of PTP-1B was used to dock all of the compounds. The triterpenic acids may bind in a binding pocket adjacent to the catalytic site, according to docking studies. The protein-ligand complexes are stabilised by a large hydrogen bond network with the carboxyl group and Van der Waals interactions [3]. The primary components of acetonic extract from Phoradendron reichenbachianum (Loranthaceae), a medicinal plant used in Mexico to treat diabetes, are morolic (1) and moronic (2) acids. The goal of this investigation was to see if compounds 1 and 2 have sub-acute antidiabetic and antihyperlipidemic effects in a non-insulin-dependent diabetic rat model. Also, an oral glucose tolerance test was used to assess the antihyperglycemic effect on normoglycemic rats. Daily administration of morolic (1) and moronic (2) acids $(50 \mathrm{mg} / \mathrm{kg})$ reduced blood glucose levels by $60 \%$ from the first to the tenth day following treatment compared to the control group ( $\mathrm{p} 0.05)$. Furthermore, blood samples from diabetic rats revealed that both substances reduced plasmatic cholesterol (CHO) and triglyceride (TG) concentrations, restoring them to normal levels (p0.05). Also, compared to the control group, pretreatment with $50 \mathrm{mg} / \mathrm{kg}$ of each drug resulted in a substantial antihyperglycemic impact following glucose and sucrose loading $(2 \mathrm{~g} / \mathrm{kg})$. Compounds 1 and 2 inhibited 11 -HSD 1 activity in vitro at $10 \mathrm{M}$, according to in vitro experiments. 
In silico study of the pentaclyclic triterpenic acids on 11-HSD 1 found that all of the compounds had high docking scores and significant interactions with the catalytic region, allowing them to block the enzyme. In conclusion, in vitro and in silico studies have shown that morolic and moronic acids have a long-term antidiabetic and antihyperglycemic effect, possibly mediated by insulin sensitization with subsequent changes in glucose, cholesterol, and triglycerides, in part mediated by inhibition of 11-HSD 1 [4].

\section{Anti-AIDS agents}

Different C-3 conformationally constrained betulinic acid (BA, 1) derivatives were developed and synthesised in order to explore the conformational space of the $\mathrm{C}-3$ pharmacophore in our ongoing investigation of triterpene derivatives as effective anti-HIV medicines. Analogues of 3-0-monomethylsuccinyl-betulinic acid (MSB) were also created to better understand the role of the C-3' dimethyl group in bevirimat (2), a first-in-class HIV maturation inhibitor now undergoing phase IIb clinical trials. In addition, the backbone and C-3 alteration of another triterpene skeleton, moronic acid (MA, 3), were studied in relation to the anti-HIV action of this chemical family. This research helped us better understand the structure-activity relationships (SAR) of triterpene-derived anti-HIV drugs, leading to the design and production of compound 12 (EC(50): 0.0006 microM), which had somewhat greater HIV-1 maturation inhibitor efficacy than compound 2 [5].

Seven novel triterpene derivatives were developed, synthesised, and tested for in vitro antiviral activity as part of a continuous structureactivity relationship research of powerful anti-HIV medicines. Moronic acid derivatives 19, 20, and 21 were shown to have considerable action in $\mathrm{H} 9$ cells infected with HIV-1. In the MT-4 cell line, compounds 19 and 20 were tested against HIV-1 NL4-3 and treatment resistant strains. The antiviral properties of compounds 19 and 20 were superior to that of the betulinic acid analogue 8 (PA457), which has completed a Phase IIa clinical study. Compound 20 had EC50 values of 0.0085 microM against NL4-3, 0.021 microM against PI-R (a multiple protease inhibitor resistant strain), and 0.13 microM against FHR-2, indicating strong anti-HIV action (an HIV strain resistant to 8). Compound 20 has turned into a fresh lead for modification, and more research into 20-related compounds as clinical trial candidates is needed [2].

From Brazilian propolis, researchers extracted a novel triterpenoid called melliferone (1), three known triterpenoids, moronic acid (2), anwuweizonic acid (3), and betulonic acid (4), and four known aromatic compounds (5-8) that were evaluated for anti-HIV activity in $\mathrm{H} 9$ cells. Moronic acid (2) was modified to create more powerful anti-AIDS drugs after showing substantial anti-HIV activity (EC(50) $0.1 \mathrm{microg} / \mathrm{ml}$, TI>186) [6].

\section{Chemotherapeutic agents}

Pharmaceutical substances have always been abundant in medicinal plants. As a result, the author's research program's long-term goals are to find and create novel chemotherapeutic medicines based on plant-derived chemical leads utilising a medicinal chemistry method, which combines chemistry and biology. Sesquiterpene lactones, quassinoids, naphthoquinones, phenylquinolones, dithiophenediones, neo-tanshinlactone, tylophorine, suksdorfin, DCK, and DCP are just a few examples of promising bioactive natural products and their synthetic analogues that will be discussed in terms of their discovery and preclinical development as potential clinical trial candidates. Bioactivity-or mechanism-of-action-directed isolation and characterisation of active compounds, rational drug design-based modification and analogue synthesis, and structureactivity relationship and mechanism-of-action investigations are some of the research methods used. Bevirimat (dimethyl succinyl betulinic acid), a current clinical trial drug developed by the Natural Products Research Laboratories at the University of North Carolina, is presently in phase IIb studies for treating AIDS. Of addition, Bevirimat is the first in a new family of HIV treatment candidates known as "maturation inhibitors." In addition, an etoposide analogue, GL-331, has advanced to phase II anticancer clinical trials, while the curcumin analogue JC-9 is in phase II clinical trials for acne treatment and is being developed for prostate cancer studies [7].

\section{Virus lytic}

Epstein-Barr virus (EBV) produces two transcription factors, Rta and Zta, during the immediate-early stage of the lytic cycle to stimulate the transcription of viral lytic genes. Our immunoblotting and flow cytometry investigations indicate that moronic acid, present in galls of Rhus chinensis and Brazilian propolis, at 10 microM suppresses the production of Rta, Zta, and an EBV early protein, EA-D, after lytic induction with sodium butyrate. This study also reveals that moronic acids decreases the capacity of Rta to activate a promoter that contains a Rta-response element, showing that moronic acid interferes with the function of Rta. On the other hand, moronic acid does not appear to impact with the transactivation function of Zta. Therefore, the absence of expression of Zta and EA-D following moronic acid treatment is related to the suppression of the transactivation activities of Rta. Because the expression of Zta, EA-D and many EBV lytic genes rely on Rta, the treatment of P3HR1 cells with moronic acid greatly decreases the quantities of EBV particles generated by the cells following lytic induction. This study shows that moronic acid is a novel structural lead for anti-EBV medication development [8].

\section{Anti-HIV}

Rhuscholide A (1), a novel benzofuran lactone, was isolated from the stems of RHUS CHINENSIS, along with six other compounds: 5hydroxy-7-(3,7,11,15-tetramethylhexadeca-2,6,10,11-tetraenyl)-2(3 H)-benzofuranone (2), betulin (3), betulonic acid (4), moronic acid (5), 3-oxo-6 beta-hydroxyolean-12-en-28-oic acid (6), and 3-oxo-6 beta-hydroxyolean-18-en-28-oic acid (6), and 3-oxo-6 betahydroxyolean-18-en-28-oic acid (6) (7). The structure of rhuscholide A was determined using 1D, 2D NMR (COSY, HMQC, HMBC) and mass (EI-MS, HR-EI-MS) spectrum data (propan-2ylidene)-7-(3,7,11,15-tetramethylhexadeca-2,6,10,11-tetraenyl)-2(3 H)-benzofuranone-7-(3,7,11,15-tetramethylhexadeca-2,6,10,11tetraenyl)-2(3 H)-benzofuranone (1). Compound 1 has strong antiHIV-1 activity, with an EC50 value of 1.62 microM and a therapeutic index (TI) of 42.40, according to in vitro anti-HIV-1 bioassays. With EC50 values of $3.70,5.81,7.49$, and 13.11 microM, compounds 2, 4, 5 , and 7 demonstrated moderate anti-HIV-1 activity [9]. Morolic acid (1) is a pentacyclic triterpene found in nature, and its derivatives have anti-HIV and other biological properties. Starting with betulin, an efficient synthesis of 1 was completed in 11 stages with a total yield of 24\%. Moradiol (4), acridocarpusic acid D (5), acridocarpusic acid E (6), and moronic aldehyde (7) are some of the related natural triterpenes that have been produced. The biological assays revealed that 1,5 , and 6 had a modest inhibitory effect on glycogen phosphorylase [10].

\section{Cytotoxic activity}

Five new triterpenoids, acridocarpusic acids A-E (1-5), three known triterpenoids, moronic acid (6), ursolic acid, and oleanolic acid, and two known flavonoids, 4',5-dihydroxy-7-methoxyflavone and 4',5dihydroxy-3',7-dimethoxyflavone, were isolated from the cytotoxic $\mathrm{MeOH}$ extract obtained from Acridocarpus. On the basis of thorough 1D and 2D NMR spectroscopic data interpretation, the structures of the novel compounds 1-5 were determined. In the A2780 test, compound 3 demonstrated considerable cytotoxic action, with an IC50 of 0.7 microg/ml [11]. Through a bioassay-guided fractionation, the cytotoxic chemical moronic acid (1) and the novel tetracyclic triterpene 3,4-seco-olean-18-ene-3,28-dioic acid (2) were obtained from the aerial portions of the medicinal plant Phoradendron reichenbachianum (mistletoe, Loranthaceae). This plant species also contains squalene, glycerol trilinoleate, morolic acid, betulonaldehyde, betulinaldehyde, alpha-germanicol, lupeol, beta-sitosterol, and beta-sitosteril glucopyranoside. Chemical and spectroscopic data were used to deduce the structures [12].

\section{Anti-herpes}

Rhus javanica, a medicinal plant, has been demonstrated to have anti-HSV action in mice. We isolated two main anti-HSV chemicals, moronic acid and betulonic acid, from the herbal extract and tested their anti-HSV efficacy in vitro and in vivo. It was the main anti-HSV component in the ethyl acetate fraction. The effective concentrations 
of moronic acid and betulonic acid for $50 \%$ plaque reduction were 3.9 and 2.6 microgram $/ \mathrm{ml}$, respectively. Betulonic acid had a higher therapeutic index (10.3-16.3). (6.2). HSV-1 resistant to acyclovirphosphonoacetic acid, thymidine kinase-deficient HSV-1, and wildtype HSV type 2 were all susceptible to moronic acid. When given orally to mice infected cutaneously with HSV-1 three times daily, this chemical substantially delayed the development of skin lesions and/or lengthened mean life periods without harm. Moronic acid suppresses viral production more effectively in the brain than the skin. This was in line with longer mean survival periods. Moronic acid was isolated as a significant anti-HSV component from Rhus javanica. ACV's anti-HSV activity differed from ACV's. Moronic acid has new anti-HSV action that was consistent with the extract in HSVinfected mice [13].

\section{Antimicrobial activity}

Ozoroa mucronata root bark extract demonstrated antibacterial action against Gram-positive bacteria. The active component C30H46O3 was isolated from the extract during bioassay. Spectroscopic investigations revealed the first natural olean-18-ene keto acid structure 1 („moronic acid”). This bioactive triterpene has a simple structure[14]. A native of Rio Grande do Sul (Southern Brazil), Schinus lentiscifolius Marchand has been used in Brazilian traditional medicine as an antiseptic and antibacterial to treat a variety of health issues, including leucorrhea and ulcer and wound healing. Although it is a frequently used herb, there are no research to support it [15].

\section{Ribosome-loaded mRNAs}

The study of ribosome-loaded mRNAs (i.e., the translatome) is valuable for determining the role of post-transcriptional regulatory mechanisms in the pharmacological effects of phytocompounds in immune cells. We examined the effects of pachymic acid from the Poria cocos fungus and moronic acid from propolis on the translatomes of THP-1 macrophages exposed to bacterial lipopolysaccharide (LPS) with those of hydrocortisone to find clues to their biological effects. DNA microarray analysis of polysomeassociated RNAs obtained from cells treated for $3 \mathrm{~h}$ with LPS plus each of the drugs was followed by studies of pathways/gene ontologies (GO). Real-time PCR was used to assess upregulated mRNAs in enriched pathways that were discovered to include AUUUA (AU)-rich motifs, and Western blotting was used to verify expression of potential RNA-binding proteins stabilizing/destabilizing such AU-rich mRNAs. For moronic acid, 23 and 2 for pachymic acid, and 214 and 59 for hydrocortisone therapy, the numbers of upregulated and downregulated genes (fold-changes2.0 vs vehicle-control) were respectively 209 and 125, 23 and 2 for pachymic acid, and 214 and 59 for hydrocortisone treatment [16].

\section{CONCLUSION}

Moronic acid is a pentacyclic triterpene derived from the sumac plant Rhus javanica, which has long been thought to have therapeutic properties. Various studies on its pharmacological effects have sparked interest in health-promoting characteristics like as Antidiabetic activity, Anti-AIDS agents, Chemotherapeutic agents, Virus lytic, Anti-HIV, Cytotoxic activity, Anti-herpes, Antimicrobial activity, Ribosome-loaded mRNAs.

\section{ACKNOWLEDGMENT}

It's our privilege to express profound sense of gratitude and cordial thanks to our respected chairman Mr. Anil Chopra, Vice Chairperson Ms. Sangeeta Chopra and Pro-Chairman Mr. Prince Chopra, St. Soldier Educational Society, Jalandhar for providing the necessary facilities to complete this work.

\section{FUNDING}

Nil

\section{AUTHORS CONTRIBUTIONS}

All the authors have contributed equally.

\section{CONFLICTS OF INTERESTS}

Declared none

\section{REFERENCES}

1. National Center for Biotechnology Information. PubChem Compound Summary for CID 489941. Available from: https://moronicacid.ncbi.nlm.gov/compound/Moronic-acid. [Last accessed on 17 Jul 2021]

2. Yu D, Sakurai Y, Chen CH, Chang FR, Huang L, Kashiwada Y, Lee KH. Anti-AIDS agents 69. Moronic acid and other triterpene derivatives as novel potent anti-HIV agents. J Med Chem. 2006;49(18):5462-9. doi: 10.1021/jm0601912, PMID 16942019.

3. Ramírez-Espinosa JJ, Rios MY, López-Martínez S, López-Vallejo F, Medina-Franco JL, Paoli P, Camici G, Navarrete-Vázquez G, Ortiz-Andrade R, Estrada-Soto S. Antidiabetic activity of some pentacyclic acid triterpenoids, role of PTP-1B: in vitro, in silico, and in vivo approaches. Eur J Med Chem. 2011;46(6):2243-51. doi: 10.1016/j.ejmech.2011.03.005, PMID 21453996.

4. Ramírez-Espinosa JJ, García-Jiménez S, Rios MY, Medina-Franco JL, López-Vallejo F, Webster SP, Binnie M, Ibarra-Barajas M, Ortiz-Andrade R, Estrada-Soto S. Antihyperglycemic and subchronic antidiabetic actions of morolic and moronic acids, in vitro and in silico inhibition of $11 \beta$-HSD. Phytomedicine. 2013;20(7):571-6. doi: 10.1016/j.phymed.2013.01.013, PMID 23453304.

5. Qian K, Kuo RY, Chen CH, Huang L, Morris-Natschke SL, Lee KH. Anti-AIDS agents 81. Design, synthesis, and structure-activity relationship study of betulinic acid and moronic acid derivatives as potent HIV maturation inhibitors. J Med Chem. 2010;53(8):3133-41. doi: 10.1021/jm901782m, PMID 20329730.

6. Ito J, Chang FR, Wang HK, Park YK, Ikegaki M, Kilgore N, Lee KH. Anti-HIV activity of moronic acid derivatives and the new melliferone-related triterpenoid isolated from Brazilian propolis. J Nat Prod. 2001;64(10):1278-81. doi: 10.1021/np010211x, PMID 11678650.

7. Lee KH. Discovery and development of natural product-derived chemotherapeutic agents based on a medicinal chemistry approach. J Nat Prod. 2010;73(3):500-16. doi: 10.1021/np900821e, PMID 20187635.

8. Chang FR, Hsieh YC, Chang YF, Lee KH, Wu YC, Chang LK. Inhibition of the Epstein-Barr virus lytic cycle by moronic acid. Antiviral Res. 2010;85(3):490-5. doi: 10.1016/j.antiviral.2009.12.002, PMID 19969023.

9. Gu Q, Wang RR, Zhang XM, Wang YH, Zheng YT, Zhou J, Chen JJ. A new benzofuranone and anti-HIV constituents from the stems of Rhus chinensis. Planta Med. 2007;73(3):279-82. doi: 10.1055/s-2007-967113, PMID 17290322.

10. Zhang P, Hao J, Liu J, Zhang L, Sun H. Efficient synthesis of morolic acid and related triterpenes starting from betulin. Tetrahedron. 2009;65(22):4304-9. doi: 10.1016/j.tet.2009.03.100.

11. Cao S, Guza RC, Miller JS, Andriantsiferana R, Rasamison VE, Kingston DG. Cytotoxic triterpenoids from Acridocarpus vivy from the Madagascar rain forest. J Nat Prod. 2004;67(6):986-9. doi: 10.1021/np040058h, PMID 15217279.

12. Rios MY, Salina D, Villarreal ML. Cytotoxic activity of moronic acid and identification of the new triterpene 3, 4-seco-olean18-ene-3, 28-dioic acid from Phoradendron reichenbachianum. Planta Med. 2001;67(5):443-6. doi: 10.1055/s-2001-15823, PMID 11488459.

13. Kurokawa M, Basnet P, Ohsugi M, Hozumi T, Kadota S, Namba T, Kawana T, Shiraki K. Anti-herpes simplex virus activity of moronic acid purified from Rhus javanica in vitro and in vivo. J Pharmacol Exp Ther. 1999;289(1):72-8. PMID 10086989.

14. Hostettmann-Kaldas M, Nakanishi K. Moronic acid, a simple triterpenoid keto acid with antimicrobial activity isolated from Ozoroa mucronata. Planta Med. 1979;37(4):358-60. doi: 10.1055/s-0028-1097349, PMID 538108.

15. Gehrke IT, Neto AT, Pedroso M, Mostardeiro CP, Da Cruz IB, Silva UF, Ilha V, Dalcol II, Morel AF. Antimicrobial activity of Schinus lentiscifolius (Anacardiaceae). J Ethnopharmacol. 2013;148(2):486-91. doi: 10.1016/j.jep.2013.04.043, PMID 23684720. 
16. Kakegawa T, Yoshida LS, Takada M, Noguchi M, Yasukawa K, Takano-Ohmuro H. Comparison of the effects of pachymic acid, moronic acid and hydrocortisone on the polysome loading of
RNAs in lipopolysaccharide-treated THP-1 macrophages. J Nat Med. 2019;73(1):190-201. doi: 10.1007/s11418-018-1260-4, PMID 30414015 